\title{
A comparison of caspase 3 expression in the endocrine and exocrine parts of the pancreas after cladribine application according to the "leukemic" schema
}

\author{
Ludwik Jasinski, Patrycja Chylinska-Wrzos, Marta Lis-Sochocka*, \\ EWELINA WAWryK-GAWDA, BARbara JodLOWSKA-JEDrYCH
}

Chair and Department of Histology and Embryology with Experimental Cytology Unit, Medical University of Lublin, Radziwillowska 11, Poland

\begin{tabular}{|c|}
\hline ARTICLE INFO \\
\hline $\begin{array}{l}\text { Received } 18 \text { January } 2017 \\
\text { Accepted } 09 \text { March } 2017\end{array}$ \\
\hline $\begin{array}{l}\text { Keywords: } \\
\text { cladribine, } \\
\text { pancreas, } \\
\text { caspase 3, } \\
\text { apoptosis. }\end{array}$ \\
\hline
\end{tabular}

ARTICLE INFO

Received 18 January 2017

Keywords:

cladribine,

\begin{abstract}
The therapeutic effects of the immunosuppressive agent, cladribine, have been demonstrated by its toxicity to cells. However, its effects on healthy cells of the body is poorly understood. The aim of study was, hence, to, firstly, evaluate the morphology of the endocrine and exocrine pancreas after the administration of cladribine according to the "leukemic" schema, and, secondly, to assess its impact on the intensity of apoptosis. The experiment was carried out on female Wistar rats which were placed within the control group KA, and the experimental groups: A and A-bis. In the experimental groups, Cladribine was administered according to the cycle used to treat human hairy cell leukemia. In group A, the material was taken 24 hours after administration of the last dose of the drug, while in group A-bis, this was done after a 4 weeks break.

The reaction was assessed to be average in $80 \%$ of all cells in group $\mathrm{A}$, and in $64 \%$ of all acinar cells in group KA, while in group A-bis, the majority of the exocrine cells demonstrated a lack of immunohistochemical response (72\%). Moreover, most endocrine cells $(60 \%)$ in group A-bis revealed a strong reaction, while in Group A, the corresponding figure is a little over $34 \%$. A comparison of the severity of the caspase 3 expression in both the exocrine and endocrine pancreas showed significant differentiation results between the group KA and group A-bis, and between group A and A-bis $(\mathrm{p}<0.0001)$.

In can be concluded that endocrine cells are more sensitive to cladribine than are exocrine cells.
\end{abstract}

\section{INTRODUCTION}

The pancreas, like other organs and glands, is highly sensitive to the many harmful factors it is exposed to. This may result in diverse pathological processes within the organ. One of these is pancreatic cancer. This represents $3 \%$ of all malignant tumors, and it is considered one of the most dangerous and frequent cancers in humans. Indeed, the 5-year survival rate is estimated to be less than $5 \%$, and pancreatic cancer is responsible for approximately 250 thousand deaths per year. Due to the current inefficient therapeutic effects, as well as the ambiguity of cancer of the pancreas, research is on-going. In a number of studies devoted to such cancers, importance has been attributed to an analysis

\footnotetext{
* Corresponding author

e-mail: martasochocka@wp.pl

phone: +48 814486153
}

of the cell cycle, as well as the processes related to cell death $[9,18,23,28]$. These processes play a crucial role in the course of the disease, and immunohistochemical testing has become a useful tool in their assessment.

Apoptosis is a dynamic series of morphological, biochemical and molecular processes (initially requiring energy input) responsible for the death of cells, and is carried out in accordance to the information stored in the cell genome. The genes initiating this process are i.a.: p-53, mdm2, Bcl-xS, Bax, Bak, Bim, Nix, NoXABcl-gs, while the genes that inhibit apoptosis include i.a.: bcl-2, Bcl-wMcl-1 and Bcl-B $[4,14]$. The apoptosis pathways, according to the signal of initiation, are either extra - or intrinsic, and the course of apoptosis can be divided into two main stages. The first stage is the induction, the subsequent stage is the execution or performance of apoptosis. The specific steps of apoptosis 
depend on many different factors. The first (initiation) stage is induced by the initiation signal corresponding to the physiological cell death process, while the second (execution) stage comes about through the activation of a number of enzymes (the proteases called caspases). Depending on the stage (which involves various proteases), these are either initiator caspases or effectors [20,31]. The initiator caspases include the following: 1, 2, 4, 5, and 8-13, and the effector caspases (which are involved in the execution phase of apoptosis) are 3, 6, 7 and 14. Caspase 3 is an important caspase in this process. As it is directly involved in the collapse of intracellular structures, thus leading to the formation of apoptotic bodies, an evaluation of its activity is used to measure the severity of apoptosis in cells $[1,7,21]$.

Cladribine (2-chlorodeoxyadenosine, 2-CdA) is a purine analog that is cytostatic, and is often used in the treatment of neoplastic diseases, in particular, that within the white blood system $[13,26]$. The activity of $2-\mathrm{CdA}$ is associated with the toxicity of 2-CdATP (triphosphorane 2-chlorodeoxiadenosine) towards intracellular structures. In proliferating cells, 2-CdATP upsets the balance of 2-CdA deoxynucleotide, ribonucleotide reductase inhibiting activity, as well as the activity of DNA polymerases. It also disrupts the DNA structure by building the chain thereof, and such a state is a signal for termination. In contrast, in cells that are at rest, 2CdATP accumulation interferes with the intracellular pool of deoxynucleotide triphosphate, hence, inducing the activation of endonucleases. In turn, endonuclease leads to the formation of cracks in the strands of DNA repair mechanisms that initiate and activate the politransferasis enzyme. Subsequent recovery processes then lead to the depletion of energy NAD (Nicotinamide adenine dinucleotide) stocks, the inhibition of ATP synthesis, as well as the breakdown of energy processes. This results in cell death by apoptosis. 2-CdA tri-phosphate is also an inhibitor of DNA synthesis, and it brings about cell cycle arrest $[6,15]$.

Serious adverse effects are associated with cancer chemotherapy. Besides vomiting, mucosa ulceration and bone marrow aplasia, pancreatitis is a possible complication, especially in childhood cancer treatment [30], and there are cases of chemotherapy-induced acute pancreatitis in pancreatic carcinoma, ovarian cancer, as well as in acute lymphoblastic leukemia [16,25,27]. Acute pancreatitis may lead to complications such as pancreatic necrosis and the formation of pseudocysts [30]. Moreover, the destruction of the exocrine part of the pancreatic tissue leads to digestive disorders, and necrosis of the pancreatic islets may bring about glucose intolerance. What is more, chemotherapy may induce diabetes [2], as cancer chemotherapy may decrease insulin sensibility or increase gluconeogenesis. Prognosis of patients with cancer and diabetes is poorer and more complicated, therefore, chemotherapy patients need to be frequently tested for glycaemia [10].

2-CdA is a widely used listed immunosuppressive/chemotherapeutic agent in the treatment of leukemia. It has also been shown to have beneficial effects in the treatment of patients with multiple sclerosis. Still, while the therapeutic effects of 2-CdA have been demonstrated by its toxicity to cells, yet in contrast, the effects of the drug on healthy cells of the body is poorly understood. Because of the lack of reports in the literature devoted to the action of 2-CdA on the pancreas of healthy living organisms, the aim of this study was to evaluate the morphology of endocrine and exocrine pancreas after administration of 2-CdA in the "leukemic" model, and to assess the impact of the application of 2-CdA with regard to the intensity of apoptosis, on the basis of caspase 3 expression (the enzyme crucial to apoptosis execution and completion $[1,21])$.

\section{MATERIAL AND METHODS}

The experiment was carried out on white female Wistar rats weighing about $250 \mathrm{~g}$. Selection of sex of animals was associated with conducting further research related to the female reproductive system. During the experiment, the animals were housed in identical conditions and they were fed standard, granular feed LSM and had free access to drinking water. To carry-out the experiment, we received consent no 126/2001, issued by the $1^{\text {st }}$ Local Ethical Committee for Experiments of Animals of Medical University in Lublin.

The animals were placed within one control and two experimental groups -5 rats in each group. After the end of the experiment, the animals were decapitated, and material for the research were taken. In this experiment, 2-CdA was administered according to the cycle used to treat hairy cell leukemia in humans. Thus, 2-CdA (Biodribin - Institute of Biotechnology and Antibiotics) was administered in solution once a day, in the morning, subcutaneously in the dose: $0.1 \mathrm{mg} / \mathrm{kg}$ by weight, for 7 consecutive days. The groups differed in the following way:

Group A (experimental) - the material was taken 24 hours after administration of the last dose of the drug.

Group A-bis (experimental) - the material was taken after a 4 week break in the administration of the drug. During the break, the animals were fed with standard granulated fodder and had free access to drinking water.

Group KA (control) - the animals remained on the standard diet and received subcutaneous injections of physiological saline in the same volume as the administered drug in groups A and A-bis. The animals of group KA were decapitated 24 hours after administration of the last injection.

After decapitation, the pancreases samples were taken for histological and IHC (immunohistochemical examination), and were first fixed in a $10 \%$ solution of buffered formalin at $\mathrm{pH}=7$, then dehydrated in alcohol with increasing concentration, and subsequently placed in paraffin. The resulting paraffin blocks (Histosec paraffin, Merck) were cut on the rotational microtome (Leica RM 2135), in $5 \mu \mathrm{m}$ sections which were stained with hematoxylin and eosin (H\&E) [17].

The IHC study of the pancreas was carried out with the use of Anti-Casp3 antibodies (Novocastra, NCL-CPP32 Anti-Casp3 antibody produced in mice). The IHC reaction was carried out according to the indirect immunoperoxidase method.

The pancreas samples were placed on Polysine slides, and then were deparaffined and placed in xylene. These were dehydrated in a series of alcohols with decreasing concentration, and, subsequently rinsed with distilled water for 5 minutes. A thermal method was used to unveil the 
antigenic sites. Herein, samples were incubated in a citrinian buffer solution and placed within a microwave for 3 cycles (5 minutes - each). After the return to room temperature, the material was rinsed in distilled water. Later, the activity of endogenous peroxidase was blocked by placing the preparations in a mixture of $0.03 \%$ hydrogen peroxide with methanol, for the duration of 10 minutes. The samples were then washed in distilled water and TBS buffer (Trisbuffered Saline), pH 7.4. Following this, the antigen Normal Diluted Serum approach was employed to block places of nonspecific binding. The subsequent stage of the procedure involved incubation with the primary antibody for a period of 60 minutes, as diluted per the recommendation of the manufacturer $(1: 40)$.

In a later stage, the specimens were rinsed in TBS buffer. In order to mark reaction sites, we utilized a diaminobenzidine substrate solution (DAB) to generate a hematoxylin tinge. The samples were then rinsed in running water and distilled in a series of alcohols with increasing concentration, and, finally, enclosed within a coverslip [17]. A negative control was undertaken via the elimination of used antibodies.

The material was observed using the light microscope at magnification $200 \times$ and $400 \times$. The examined material were also analyzed by way of an Olympus BX41 system with digital camera DP 25 . All calculations were done via $\mathrm{Cell}^{\wedge} \mathrm{D}$.

In the IHC study, we ascertained the severity of the color reaction. Under $400 \times$ magnification, we selected the 3 fields of vision that demonstrated the highest volume of color reaction. In this evaluation, we utilized about 50 cells of the endocrine and exocrine parts of the pancreas samples. Among the cells displaying a positive reaction, we investigated the intensity of protein expression according to the following scale: $0(0)$ - no response, $1(+)$ - poor expression, $2(++)$ - average expression, and $3(+++)-$ strong expression. We then calculated the percentage of cells showing positive reaction in the different fields of view.

\section{Statistical methods}

The obtained results were summarized in tables which display the percentages of the severity of the color IHC reaction in the various groups. The comparison of the results of many independent trials was built upon the use of the Kruskal-Wallis non-parametric test. Significance was set at $\mathrm{p}<0.05[19,29]$. The analysis was performed via the Statistica program 10.

\section{RESULTS}

\section{H\&E staining (hematoxylin \& eosin)}

All pancreatic samples from groups: KA, A and A-bis (as stained by $\mathrm{H} \& \mathrm{E}$ ) revealed that, structurally, there was no abnormality (Fig. 1a, 1b and 1c). Moreover, in all the experimental groups, the acinar part of the exocrine pancreas showed an affinity for alkaline dyes in the basal part of the cell, these staining a dark blue color. Furthermore, in the cytoplasm of the treated groups, the cell nuclei showed a spheroid form. Herein, the apex of the cells facing the lumen of the acinus showed an affinity for acidic dyes (staining pink) (Fig. 1a, 1b and 1c). In group A, the single cells of the endocrine part of the pancreas that were lying both in the central and peripheral part of the isles, showed the characteristics of vacuolar degeneration. In addition, parts of the cells (mostly in the peripheral parts of the islands) contained pyknotic nuclei (Fig. 1b). However, the structure of the exocrine ducts was correct in all the investigated groups. Still, in group A-bis, the parenchyma of the organ was more dense (Fig. 1c), when compared to that of the KA group, and this effect was also seen in the samples obtained from group A. Moreover, in group A-bis and group A, the cytoplasm of single cells located within the endocrine part of the pancreas showed vacuolar degeneration. Herein, the boundaries between some of the cells were blurred, and most of the islet cells have pyknotic cell nuclei (Fig. 1b and 1c).

\section{Expression of caspase 3}

In the analysis of the pancreatic samples after the IHC reaction with antibodies directed against caspase 3 , in both experimental groups and in the KA group, a positive reaction was seen in all parts of the gland. In the group KA, an average reaction was evident in the cytoplasm of the acinar cells drawn from the exocrine part of the gland, while, most of the islet cells showed a positive reaction of high intensity (when compared to the cells obtained from the exocrine). In all cases, the reaction was cytoplasmic. Moreover, single pancreatic islet cells were unresponsive (Fig. 2a). In group A, the acinar cells showed an average $(++)$ reaction (visible in both the nucleus and the cytoplasm), while some of these cells demonstrated unresponsiveness (Fig. 2b). However, in both experimental groups, most endocrine cells revealed a positive response of different severity (Fig. $2 b$ and $2 c$ ). In addition, in both experimental groups, the majority of the cells of this part of the organ showed a strong $(+++)$ positive reaction, the remaining cells revealing less response (Fig. $2 \mathrm{~b}$ and 2c). Regarding group A-bis, we observed a low-intensity reaction in parts of the cells of the acinus. In addition, a brown staining was evident in the cytoplasm of these cells, and some cells had no IHC response. In contrast, a strong $(+++)$ positive, cytoplasmic reaction was noticeable in the cells forming the endocrine part of the pancreas (Fig. 2c).

\section{Statistical analysis}

Statistical analysis of the results has disclosed that in group A-bis, the majority of the exocrine cells demonstrated a lack of IHC response (72\%) to antibodies directed towards caspase 3 . In contrast, an average reaction (++) was observed in $80 \%$ of all cells in group A, and in $64 \%$ of all acinar cells in the group KA. In addition, in both groups A and A-bis, there were no cells showing a strong (+++) reaction, while in group KA, $9 \%$ of all exocrine cells had such an intensity of reaction (Fig. 3a). Regarding the endocrine cells, in group A-bis, most endocrine cells ( $60 \%$ of all) showed a strong reaction. In group $\mathrm{A}$, the corresponding figure is a little over $34 \%$. By contrast, in the group KA, the majority of pancreatic islet cells (77.36\%) showed an average response $(++)$, while the corresponding figures for group A and group A-bis, are $28 \%$ of all cells, and over $30 \%$ of all cells, respectively (Fig. 3b). 


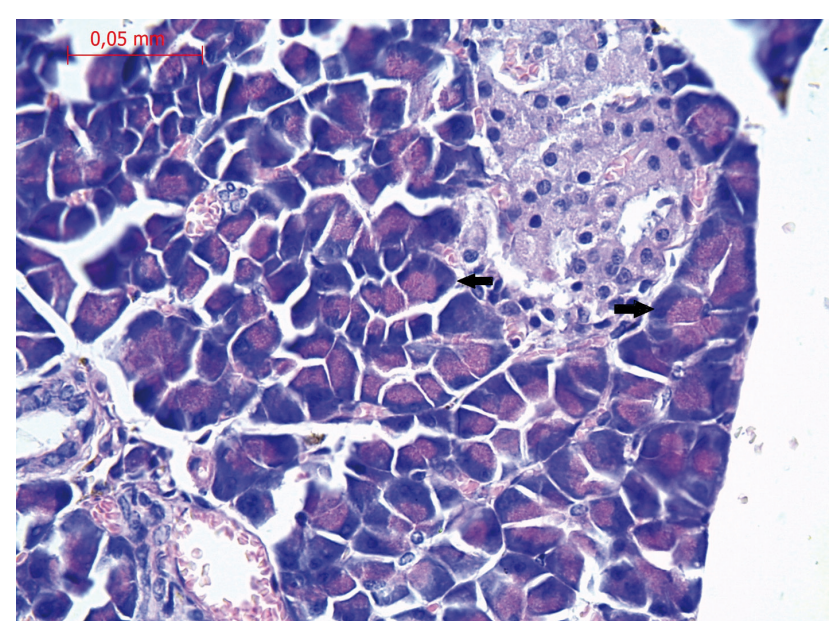

Figure 1a. Control group KA. The acinar part of the exocrine pancreas showed an affinity for alkaline dyes in the basal part of the cell, while the apex of the cells facing the lumen of the acinus showed an affinity for acidic dyes (black arrows). H\&E staining

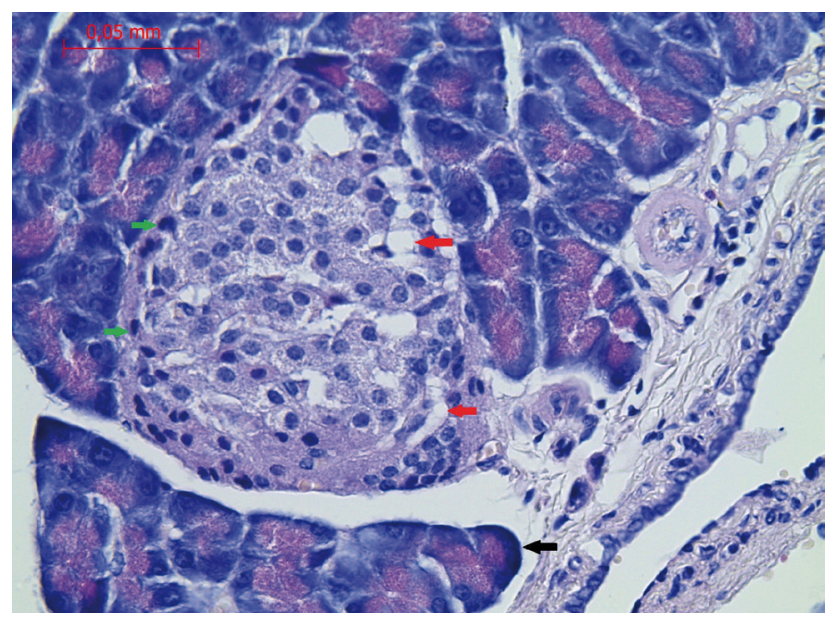

Figure 1b. Experimental group A. The acinar cells showed an affinity for alkaline dyes in the basal part of the cell, while the apex of the cells facing the lumen of the acinus showed an affinity for acidic dyes (black arrow). The single endocrine cells showed vacuolar degeneration (red arrows). In addition, parts of the cells (mostly in the periphery of isles) contained pyknotic nuclei (green arrows). H\&E staining

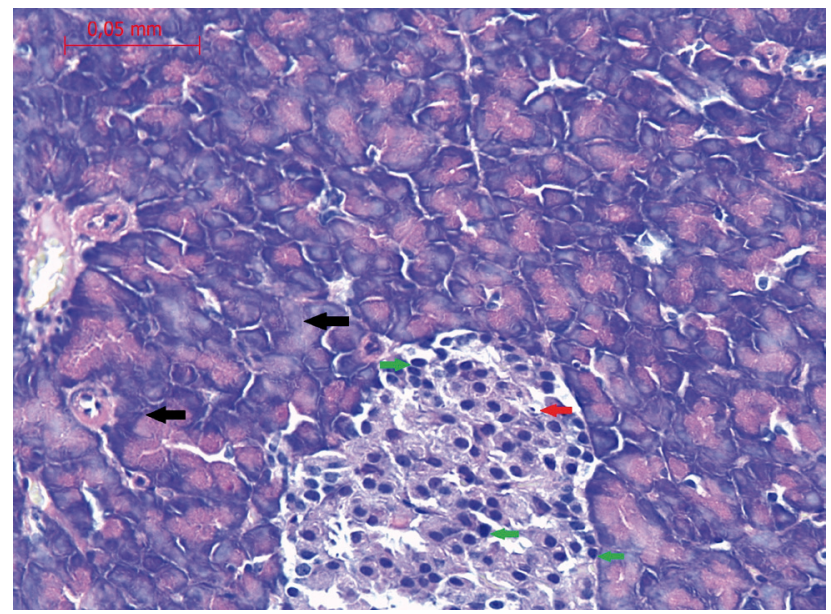

Figure 1c. Experimental group A-bis. The parenchyma of the exocrine part was evidently of greater density (black arrows). The cytoplasm of single endocrine cells showed vacuolar degeneration (red arrow). Most of the islet cells had pyknotic cell nuclei (green arrows). H\&E staining

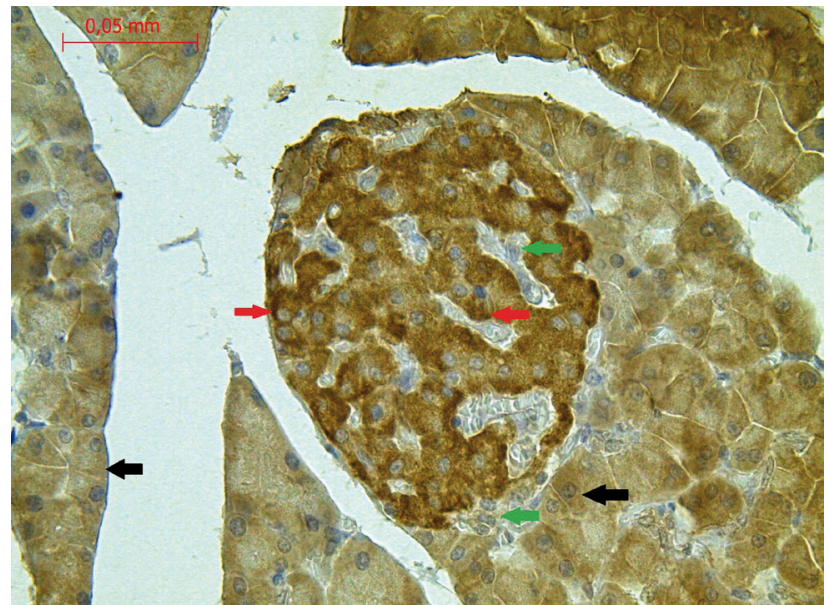

Figure 2a. Control group KA. An average reaction was evident in the cytoplasm of the acinar cells (black arrows). Most of the islet cells showed a positive average reaction (red arrows). Single pancreatic islet cells were unresponsive (green arrows)

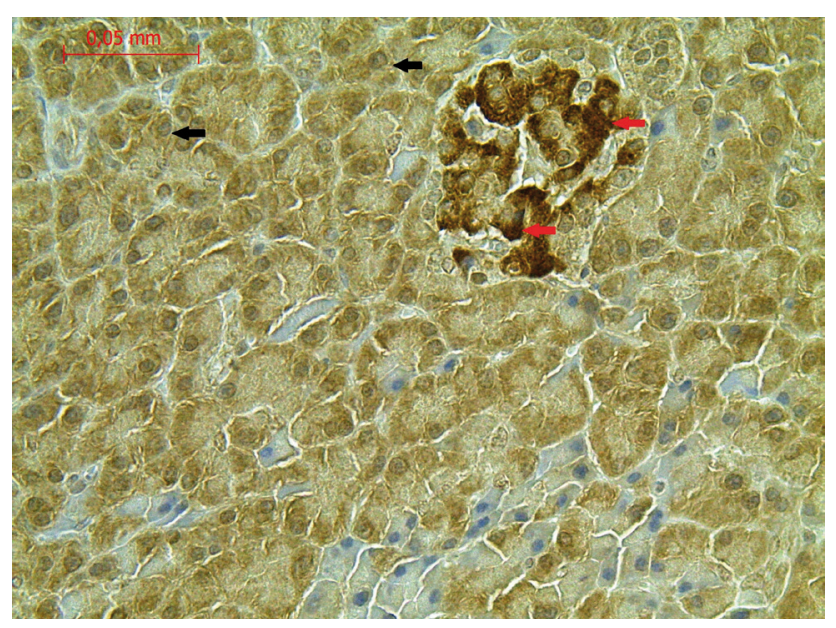

Figure $2 \boldsymbol{b}$. Experimental group A. The acinar cells showed an average $(++)$ reaction in both the nucleus and the cytoplasm (black arrows). A strong $(+++)$ positive reaction was evident in the majority of the endocrine cells(red arrows)

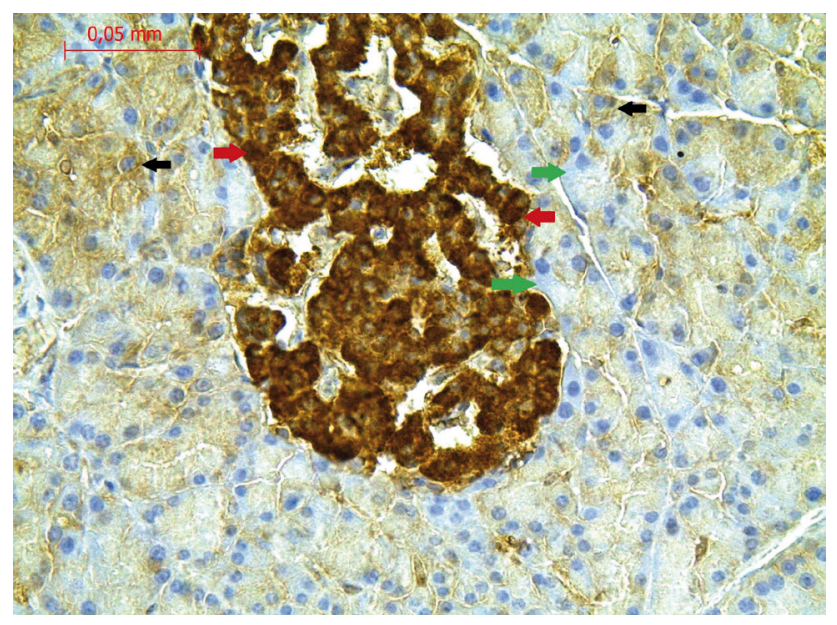

Figure 2c. Experimental group A-bis. A low-intensity reaction was seen in parts of the cytoplasm cells of the acinus (black arrows), while some cells did not display an immunohistochemical response (green arrows). A strong $(+++)$ positive cytoplasmic reaction was noticeable in the cells forming the endocrine part of the pancreas (red arrows) 


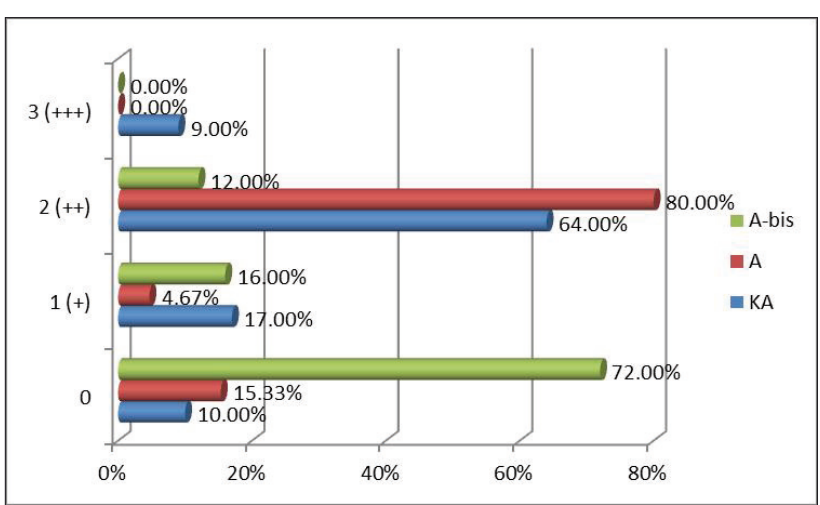

Figure $3 \boldsymbol{a}$. The intensity of caspase 3 expression in the exocrine portion of the pancreas. An average reaction $(++)$ was observed in $80 \%$ of all cells in Group A, and in $64 \%$ of the cells in the Control Group KA. In both Groups A and A-bis, there were no cells showing a strong $(+++)$ reaction, while in Group KA, 9\% of all cells displayed a strong $(+++)$ intensity of reaction

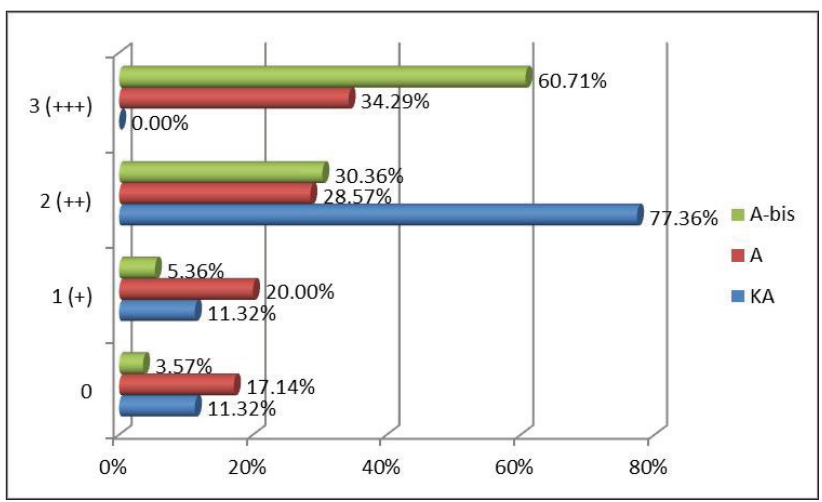

Figure $3 \boldsymbol{b}$. The intensity of caspase 3 expression in the endocrine portion of the pancreas. A strong reaction was seen in $60.71 \%$ of all cells of Group A-bis, and in $34.29 \%$ of all cells of Group A. In the Control group (KA), $77.36 \%$ of cells showed an average response (++), as did $28.57 \%$ of all cells of Group A and over $30 \%$ of all cells of Group A-bis

A comparison of the severity of the caspase 3 expression in both the exocrine and endocrine parts of the pancreas in the test groups showed significant differentiation results between the KA group and group A-bis, and between group A and A-bis $(p<0.0001)$. However, when comparisons are made between the KA group and group A, there were no significant differences in the severity of expression of caspase 3 (Tab. 1).

\section{DISCUSSION}

Rogalińska et al. has demonstrated that in contrast to healthy cells, cancer cells are more sensitive to the action of certain cytostatic agents [24]. Moreover, Ricci has found that conventional chemotherapeutic agents, not only induce apoptosis, but also bring about other forms of cell removal such as autophagy, necrosis and mitotic error, and such agents stimulate the effect of aging in the cells [22]. What is more, Burgoyne has revealed that the chromatin of eukaryotic cells nuclei exhibits different degrees of condensation depending on the state of the activity, and that heavily condensed pyknotic nuclei are characterized for dying cells or dead cells [5]. However, few reports exist in the available literature on the actual effect of chemotherapy agents on healthy cells. Still, in some studies, by way of in vivo experiments utilizing mononuclear blood cells and cell lines of chronic lymphocytic leukemia (CLL), the effect of 2-CdA and R-roscovitine (inducers of apoptosis) has been demonstrated on the process of apoptosis in the cytostatic environment. The results of such work showed a smaller degree of induction of apoptosis in "normal" cells, as compared with leukemia cells. Thus, 2-CdA and R-rosvitine are considered potential treatment options for patients with CLL [24].

While 2-CdA has been widely investigated in relation to the white blood cell system, there are few reports of its effects upon other tissues. It is known, however, that 2-CdA is cytostatic, and can induce the apoptosis of tumor cells. Furthermore, this drug is recognized as inhibiting the enzymes (mainly polymerase- $\beta$ ) involved in repairing the DNA of damage leukemia cells [12,32]. In the work of Wawryk-Gawda et al. that was conducted on female white Wistar rats, when administered according to the treatment regime of human hairy cell leukemia, 2-CdA induced apoptosis in the epithelial cells of the fallopian tube. Moreover, regarding the expression of caspase 3 , they observed that in a group of animals that were decapitated $24 \mathrm{~h}$ after the last dose of the drug, a majority of cells displayed a strong reaction [33]. Jędrych et al. [11], in a follow-up study utilizing 2-CdA according to the same model, noted the expression of caspase 3 in ovarian epithelial cells. Moreover, Chylińska-Wrzos et al., upon administering 2-CdA to male Wistar rats according to the SM treatment regime in humans, saw that in a group of animals decapitated $24 \mathrm{~h}$ after the last dose of the drug, most cells of the epidermis displayed an average to strong expression of caspase 3 [8].

In our current study, we examined the effect of 2-CdA administration on the pancreas of female Wistar rats. Herein, the microscopic study of the pancreas when stained by H\&E showed that upon 2-CdA administration, the architecture of the pancreas does not deviated from the norm. In groups A and A-bis, the image was similar. Still, the exocrine part of the pancreas have more compact structure when compared to the KA group. Moreover, in some islet cells (especially from group A), we saw some vacuolar degeneration of the cytoplasm, and we observed cells with pyknotic nuclei (which were more numerous in group A-bis). In contrast, such pyknotic cells are normally found in the peripheral

Table 1. The severity of caspase 3 expression: p-value for multiple comparisons

\begin{tabular}{|c|c|c|c|c|c|c|c|}
\hline \multirow{2}{*}{$\begin{array}{c}\text { Exocrine part } \\
\text { Groups }\end{array}$} & \multicolumn{3}{|c|}{$\begin{array}{l}\text { Kruskal-Wallis non-parametric test: } \\
\mathrm{H}(6, \mathrm{~N}=2100)=696,6655 ; \mathrm{p}=0,000\end{array}$} & \multirow{2}{*}{$\begin{array}{c}\text { Endocrine part } \\
\text { Groups }\end{array}$} & \multicolumn{3}{|c|}{$\begin{array}{l}\text { Kruskal-Wallis non-parametric: } \\
\mathrm{H}(6, \mathrm{~N}=332)=151,0112 ; \mathrm{p}=0,000\end{array}$} \\
\hline & $\begin{array}{c}\text { KA } \\
\mathrm{R}: 1469,6\end{array}$ & $\begin{array}{c}\text { A } \\
\text { R: } 1444,0\end{array}$ & $\begin{array}{c}\text { A-bis } \\
\text { R: } 637,50\end{array}$ & & $\begin{array}{c}\text { KA } \\
\mathrm{R}: 158,23\end{array}$ & $\begin{array}{c}\mathrm{A} \\
\mathrm{R}: 173,94\end{array}$ & $\begin{array}{c}\text { A-bis } \\
\text { R: } 242,07\end{array}$ \\
\hline KA & & 1,000000 & $0,000000 *$ & $\mathrm{KA}$ & & 0,751769 & $4,558221^{*}$ \\
\hline A & 1,000000 & & $0,000000 *$ & A & 0,751769 & & $3,294095^{*}$ \\
\hline A-bis & $0,000000 *$ & $0,000000 *$ & & A-bis & $4,558221 *$ & $3,294095^{*}$ & \\
\hline
\end{tabular}


part of the islands. In our study, in material drawn from both experimental groups and the control, caspase 3 expression, hence, the confirmation of apoptosis, was observed within the endocrine and exocrine parts of the pancreas. Herein, the group KA specimens displayed in the exocrine of the pancreas, the largest percentage of cells expressing this protein $(90 \%)$. In contrast, in group A, more than $80 \%$ of all cells reflected the expression of caspase 3, while in group A-bis, only about $30 \%$ did so. It must, therefore, be concluded that the number of exocrine cells involved in apoptosis had decreased. On this basis, it can be presumed that the effect of 2-CdA administered in the dose of 0.1 $\mathrm{mg} / \mathrm{kg}$ by weight for a period of 7 days, did not result in changes inside such cells. However, a slightly different picture was observed in the pancreatic islet cells. Here, the percentage of cells with positive expression of caspase 3 in group A was approximately $83 \%$ of all cells, while in group A-bis (after 4-weeks of drug interruption), the proportion of such cells increased to approximately $97 \%$ of all cells examined. Moreover, in group A-bis, the number of cells showing the severity of the test that were assessed strong $(+++)$, increased significantly from $34.2 \%$ to $60.7 \%$ of the cell total. Such an increase in the expression of caspase 3 testifies to the intensity of the apoptosis process in the cells located within this region.

Statistical analysis of the expression of caspase 3 in our study has revealed significant differences in the frequency of the severity of the IHC reaction in the cells of both parts of the pancreas, and in all treated groups $(p<0.0001)$. Herein, a comparison of the severity of the expression of caspase 3 between groups showed an important difference in the effect upon the endocrine and exocrine parts of the pancreas between groups A and A-bis, and between the group KA and A-bis $(\mathrm{p}<0.0001)$.

Anuradha et al. have observed that apoptosis in $\beta$-cells stimulates the production of various factors such as glucose, cytokines, free fatty acids, leptin and sulfonylurea [3]. These factors lead to the activation of the hexosamine and diacyloglicerole/protein kinase $\mathrm{C}$, which, in turn, brings about the release of cytokines. The released cytokines, subsequently, induce Fas protein and tumor necrosis factor-alpha (TNF- $\alpha$ ) production. That is, the afore-mentioned factors induce the apoptosis of $\beta$-cells on the extrinsic pathwaywhich is also important in the treatment of diabetes.

\section{CONCLUSION}

Cladribine given according to the guidelines of treatment for human hairy cell leukemia led to greater immediate damage to the pancreatic islet cells than it did to the acinar cells of the pancreas. 2-CdA was also seen to inhibit the process of apoptosis in the exocrine cells and to stimulate the same in the cells of the islands of Langerhans. In addition, the endocrine cells of the pancreas were noted to be more sensitive to the used chemotherapeutic drug than were its exocrine cells. Finally, the severity of apoptosis in these cells was shown to differ, and the diverse cells of the pancreas was observed to react very differently to 2-CdA. However, no major changes were seen after a 4-weeks break in the administration of the drug, when compared to the control. What is more, there were much less cells showing vacuolar degeneration of the cytoplasm, but some cell evidenced pyknotic nuclei, especially within the islands of the pancreas. Over all, 2-CdA was seen to inhibit the process of apoptosis in the exocrine cells and to stimulate the same in the cells of the islands of Langerhans. In addition, the endocrine cells of the pancreas were observed to be more sensitive to the used chemotherapeutic drug than were its exocrine cells. Finally, the severity of apoptosis in these cells was noted to differ, and the diverse cells of the pancreas was seen to react very differently to $2-\mathrm{CdA}$. Our results thus suggest that chemotherapy with cladribine can lead to disturbances of pancreatic functions, hence, patients treated with 2CDA need frequent control with regard to pancreatic enzyme levels and to prevent glycaemia.

\section{REFERENCES}

1. Abu-Qare A.W., Abou-Donia M.B.: Biomarkers of apoptosis: release of cytochrome c, activation of caspase-3, induction of 8-hydroxy-2'deoxyguanosine, increased 3-nitrotyrosine, and alteration of p53 gene. Journal of Toxicology and Environmental Health, 4, 313, 2001.

2. Adachi J. et al.: The Development of Fulminant Type 1 Diabetes During Chemotherapy for Rectal Cancer. Intern Med., 54, 819, 2015.

3. Anuradha R. et al.: Apoptosis of beta cells in diabetes mellitus. DNA Cell Biol., 33, 743, 2014.

4. Borner C.: The Bcl-2 protein family: sensors and checkpoints for life-or death decisions. Mol Immunol., 39, 615, 2003.

5. Burgoyne LA.: The Mechanisms of Pyknosis: Hypercondensation and Death. Experimental Cell Research, 248, 214, 1999.

6. Cardoen S. et al.: Effects of 2-Chloro-2'-Deoxyadenosine on the Cell Cycle in the Human Leukemia EHEB Cell Line. Nucleosides, Nucleotides \& Nucleic Acids, 23, 1425, 2004.

7. Chmielewski M., Linke K., Zabel M.: Metody wykrywania zjawiska apoptozy w komórkach wątrobowych in situ. Nowiny Lekarskie, 77, 223, 2008.

8. Chylińska-Wrzos P. et al.: Expression of p53 protein and the histomorphological view of epidermis in experimental animals after cladribine application. IJVR, 15(3), 48, 198, 2014.

9. Gryczyński M., Pietruszewska W.: Wybrane aspekty apoptozy i proliferacji komórkowej raka krtani. Otorynolaryngologia, 1, 151, 2002.

10. Jacob P., Chowdhury T.A.: Management of diabetes in patients with cancer. QJM, 108, 443, 2015.

11. Jędrych M. et al.: Immunohistochemical evaluation of cell proliferation and apoptosis markers in ovarian surface epithelial cells of cladribine-treated rats. Protoplasma, 250, 1025, 2013.

12. Johnston J.: Mechanism of action of pentostatin and cladribine in hairy cell leukemia. Leuk Lymphoma, 52, 43, 2011.

13. Kalinka-Warzocha E. et al.: Randomized comparison of cladribine alone or in combination with cyclophosphamide, and cyclophosphamide, vincristine and prednisone in previously untreated lowgrade B cell non Hodgkin lymphoma patients: final report of the Polish Lymphoma Research Group. Cancer, 113, 367, 2008.

14. Korzeniewka-Dyl I.: Kaspazy - struktura i funkcja. Pol Merkuriusz Lek., 138, 403, 2007.

15. Leist TP., Weissert R.: Cladribine: Mode of Action and Implications for Treatment of Multiple Sclerosis. Clin Neuropharm., 34, 28, 2011.

16. Linghui L., Yanni L., Huangying T.: Chemotherapy-induced fulminant acute pancreatitis in pancreatic carcinoma: A case report. Oncol Lett., 8, 1143, 2014.

17. Litwin J.A., Gajda M.: Podstawy technik mikroskopowych. Podręcznik dla studentów i lekarzy. WUJ, 2011.

18. Patnayak R. et al.: Solid and cystic papillary neoplasm of pancreas: A clinic-pathological and immunohistochemical study: A tertiary care center experience. South Asian J Cancer, 2, 153, 2013.

19. Petrie A., Sabin C.: Statystyka medyczna $w$ zarysie. PZWL, Warszawa, 2006 
20. Pop C., Salvesen G.: Human caspases activation, specifity, and regulation. J Biol Chem., 284, 21777, 2009.

21. Porter A.G., Janicke RU.: Emerging roles of caspase-3 in apoptosis. Cell Death and Differentiation, 6, 99, 1999.

22. Ricci M., Zong W.: Chemotherapeutic approaches for targeting cell death pathways. Oncologist, 11, 342, 2006.

23. Rockacy M., Khalid A.: Update on pancreatic cyst fluid analysis. Ann Gastroenterol., 26, 122, 2013.

24. Rogalińska M. et al.: R-roscovitine (Seliciclib) affects CLL cells more strongly than combinations of fludarabine or cladribine with cyclophosphamide: Inhibition of CDK7 sensitizes leukemic cells to caspase-dependent apoptosis. J Cell Biochem., 109, 217, 2010.

25. Shintani D. et al.: Acute pancreatitis induced by paclitaxel and carboplatin therapy in an ovarian cancer patient. Eur J Gynaecol Oncol., 37, 286, 2016.

26. Sigal D. et al.: Beyond hairy cell: the activity of cladribine in other hematologic malignancies. Blood, 116, 2884, 2010.
27. Sikorska-Fic B. et al.: Acute pancreatitis during chemotherapy of acute lymphoblastic leukaemia complicated with pseudocyst. Med Wieku Rozwoj., 12(4 Pt 2),1051, 2008.

28. Soreide K., Sund M.: Epidemiological - molecular evidence of metabolic reprogramming on proliferation, autophagy and cell signalling in pancreas cancer. Cancer Lett., 356, 281, 2015.

29. Stanisz A.: Biostatystyka. Podręcznik dla studentów i lekarzy. WUJ, Kraków, 2005.

30. Stefanović M. et al.: Acute pancreatitis as a complication of childhood cancer treatment. Cancer Med., 5, 827, 2016.

31. Stępień A., Izdebska M., Grzanka A.: Rodzaje śmierci komórki. Post Hig Med. Dośw., 61, 420, 2007.

32. Van den Neste E. et al.: Infectious complications after 2-chlorodeoxyadenosine therapy. Eur J Haematol., 56, 235, 1996.

33. Wawryk-Gawda E. et al.: Intrinsic apoptosis pathway in fallopian tube epithelial cells induced by cladribine. Scientific World Journal, 2, 928036, 2014 